Dilogini, R.A.A., Sridarran, P. and Mahedrarajah, G., 2021. Enhancing the integration of smart features in commercial buildings to conserve energy: A framework. In: Sandanayake, Y.G., Gunatilake, S. and Waidyasekara, K.G.A.S. (eds). Proceedings of the $9^{\text {th }}$ World Construction Symposium, 9-10 July 2021, Sri Lanka. [Online]. pp. 302-313. DOI: https://doi.org/10.31705/WCS.2021.26. Available from: https://ciobwcs.com/papers/

\title{
ENHANCING THE INTEGRATION OF SMART FEATURES IN COMMERCIAL BUILDINGS TO CONSERVE ENERGY: A FRAMEWORK
}

\author{
R.A.A. Dilogini ${ }^{1}$, P. Sridarran ${ }^{2}$ and G. Mahedrarajah $^{3}$
}

\begin{abstract}
The commercial building sector is classified as a highly energy-intensive category in Sri Lanka. Building practitioners adopt energy-saving mechanisms to minimise energy consumption. However, the integration of smart features plays a vital role in conserving energy in commercial buildings. However, Sri Lanka lags behind in the adoption of smart features when compared to other countries. To address this problem, this study aimed to develop a framework for the better integration of smart features to minimise the energy consumption of Sri Lankan commercial buildings. This research is carried out initially by literature review, and then research has been followed by case study. Data collected is analysed through manual content analysis and computer software with the aid of NVivo 12 software. Findings revealed that smart features are the new technologies evolved in commercial buildings to conserve energy. However, building practitioners faced several issues in integrating these features within the existing buildings. Limited knowledge of management, building owners and operators, high initial cost, and lack of workforce skill were identified as main barriers to integrating smart features in Sri Lankan commercial buildings. Moreover, this research identified the possible mechanisms for the better integration of smart features in commercial buildings. For better integration, it is required to plan it at the initial design stage of buildings, select reliable contractors, and raise awareness of management and client about smart features. Finally, a framework was developed for the better integration of smart features to minimise the energy consumption of Sri Lankan commercial buildings.
\end{abstract}

Keywords: Commercial buildings; Energy conservation; Energy consumption; Smart features; Sri Lanka.

\section{INTRODUCTION}

Global energy consumption has typically more than doubled in the last 40 years, and it is expected to increase by another $30 \%$ by 2040 (International Organisation for Standardization [ISO], 2018). Specifically, energy use in commercial buildings has increased in recent years (Anik et al., 2016; Central Intelligence Agency [CIA], 2019). Herein, reduce the energy consumption of commercial buildings, specifically existing buildings that account for a significant part of the building sector, has become a

\footnotetext{
${ }^{1}$ Department of Building Economics, University of Moratuwa, Sri Lanka, dilodilogini894@gmail.com

${ }^{2}$ Department of Building Economics, University of Moratuwa, Sri Lanka, psridarran@uom.lk

${ }^{3}$ Department of Building Economics, University of Moratuwa, Sri Lanka, gowsigam@uom.lk
} 
considerable priority (Fasna and Gunatilake, 2019; Kaygusuz, 2002). Similarly, in 2016, 39 percent of total energy was consumed by the Sri Lankan building sector (Vidanagama and Lokupitiya, 2018).

Smart buildings were introduced and widely utilised as the most suitable solution for high energy consumption (Madani et al., 2015; Nguyen and Aiello, 2013). On a similar note, smart buildings minimise energy consumption by 50 percent more than conventional buildings (Hojjati and Khodakarami, 2016; Brady and Abdellatif, 2017).

"Buildings that have advanced controls and sensors along with automation, communication, and analytic capabilities are known as smart buildings" (King and Perry, 2017, p. 22). Generally, this building automation becomes more attractive and feasible to potential residents by generating energy savings while meeting comfort needs (Arditi et al., 2015; Basnayake et al., 2015). In addition, smart buildings can connect with the power grid, a feature that is becoming increasingly important for the deployment of the response to utility demand (Sembroiz et al., 2019; Pathmasiri, 2010). Likewise, its features often include smart, automated, and adaptive management systems; indoor climate control systems; and energy efficiency (Gluszak et al., 2019).

As energy costs are one of the main drivers of business costs, reducing energy consumption leads to lower operating costs and improves organisations' profitability (Jayamaha, 2006; Dincer, 1999). Therefore, due to the forbidding energy situation, many countries focused more on energy conservation goals and strategies (Zhao and Magoules, 2012). Smart buildings emerge successfully and promptly in developed countries and certain developing countries as a solution for energy consumption (Verma et al., 2019).

Similarly, in Sri Lanka, the rate of commercial energy consumption was $21 \%$ compared to the other sectors (Ceylon Electricity Board [CEB], 2018). Also, Sri Lankan commercial buildings adopting several approaches to conserve energy (King and Perry, 2017). However, smart buildings are a relatively new concept and have only recently attracted the attention of researchers and industry experts as Sri Lanka lags behind in the adoption of new technology, as compared to other countries (Suriyarachchi et al., 2019). However, as a developing country, Sri Lanka should also be prepared to face the concept of a smart building (Fernando and Jayasena, 2008). Several studies concerning smart buildings in developed countries were conducted in different contexts. Despite these studies, in Sri Lanka, there is a need to investigate smart building implementation and smart feature integration as a solution for energy consumption. It is also essential to find suitable solutions and potential barriers to better implement smart features inside the building. Although several frameworks have been developed for developing countries, they cannot be fully adopted in Sri Lanka since such frameworks are context specified (Li et al., 2010). Meanwhile, challenges faced by the building practitioners in integrating the smart features and technologies are unique to Sri Lanka due to its economic scale and IT infrastructure (Atayero et al., 2016). Hence, this research aims to develop a framework for integrating smart features to minimise the energy consumption of Sri Lankan commercial buildings. 


\section{LITERATURE SYNTHESIS}

\subsection{STRATEgIES TO CONSERVE ENERGY IN BUILDINGS}

Many countries focused more on energy conservation goals and strategies due to facing the grim energy situation (Zuo et al., 2012). Chwieduk (2003) opined that improving the building envelope, advancing heat and ventilation sources, introducing heat metering and automation, and improving other installed equipment are the traditional energy-saving measures.

Zou et al. (2018) identified that the design concept, technology, construction method, and soft measures are strategies to enhance building energy performance. On another note, Zavalani (2011) and Doukas et al. (2017) said several design stage fundamental decisions and solutions such as thermal performance of building envelope, building orientation, form, thermal mass, passive heating, cooling, ventilation, daylighting, selection of adequately sized energy-efficient individual energy-using devices, building management system (BMS), building automation or smart features have a significant impact on the commercial building's energy efficiency. Besides, adopting new technology and methods has also become popular among most researchers and practitioners as one of the most effective methods to optimise energy (Zou et al., 2018; Shabha, 2006; Zhou and Yang, 2018). Also, smart buildings integrate and account for intelligence, enterprise, control, and materials and construction as an entire building system, with adaptability, not reactivity, at the core, to meet the drivers for building progression: energy and efficiency, durability, and comfort and satisfaction (Buckman et al., 2014).

\subsection{CHALLENGES AND BARRIERS IN IMPLEMENTING SMART FEATURES}

Communication between the numerous components requires 'standardisation' and 'interoperability,' which are components of key issues in smart building technology development (Mammeri and Younus, 2018). Besides, the main barriers to the development of smart building technologies are scalability, cost, flexibility, and issues related to preventive maintenance (Woradechjumroen and Li, 2015). Moreover, the building owners have inadequate knowledge as function integrators of the cooperative advancements of incorporating various technologies due to the absence of a platform for abstracting, modelling, and validating new technologies that inhibit their adoption (Mammeri and Younus, 2018). Smart buildings can centralise security, access, and security systems control and monitoring, providing an increase to concern that those systems are the target of threats to cybersecurity (Ma et al., 2016). According to Ma et al. (2016), lack of customer awareness and workforce skillsets also affect smart technology proliferation. Another barrier to the prevalence of smart buildings is that building infrastructure requires a lengthy replacement sequence (Rana et al., 2018). According to Albino et al. (2015), another barrier to the proliferation of smart buildings is the lack of seamless interoperability among linked devices.

\section{RESEARCH METHODOLOGY}

In the first stage of research, a brief literature review was carried out to identify the energy consumption ways in commercial buildings, significant causes for high energy consumption, features of the smart building concept, and energy conservation feature in smart buildings through books, conference proceedings, internet, and journals. Since it is required to collect in-depth information from professionals involved in integrating smart 
features, which cannot be understood or experienced in numerical data and statistical analysis was needed. Therefore, a qualitative approach was carried out. The data collection was conducted to fulfil the study's aim through the semi-structured interviews under the case study research design. In Sri Lanka, the application of smart features are rare. Among such rare applications, commercial buildings mostly hold the place of applications in a global context. Besides, commercial buildings were considered as the most energy-consuming buildings requiring smart integration (Weng and Agarwal, 2012). Subsequently, according to Yin (2011), the case study is used where the researcher needs an in-depth investigation in a particular area and focused on understanding the full scope of the problem, not on quantifying the problem. Therefore, five commercial buildings were selected as cases to identify the issues related to smart features integration. Table 1 presents the detailed description of selected cases.

Table 1: Profile of the selected cases

\begin{tabular}{ccccccc}
\hline Cases & \multicolumn{5}{c}{ Building Information } \\
\cline { 2 - 7 } & $\begin{array}{c}\text { Type of } \\
\text { Business }\end{array}$ & $\begin{array}{c}\text { Gross Floor } \\
\text { Area (sq. ft) }\end{array}$ & $\begin{array}{c}\text { Number } \\
\text { of Floors }\end{array}$ & $\begin{array}{c}\text { Building } \\
\text { Operation }\end{array}$ & $\begin{array}{c}\text { Number of } \\
\text { Occupants }\end{array}$ & $\begin{array}{c}\text { Expected } \\
\text { Lifetime }\end{array}$ \\
\hline C1 & Office & 70,000 & 8 & Since 2015 & 500 & 60 Years \\
C2 & Commercial & 260,000 & 11 & Since 2008 & 1,200 & 65 Years \\
C3 & Commercial & 350,000 & 13 & Since 2012 & 2,500 & 100 Years \\
C4 & Office & 500,000 & 32 & Since 1985 & 3,000 & 50 Years \\
C5 & Commercial & $1,260,000$ & $39 x 2$ & Since 1995 & 6,000 & 50 Years \\
\hline
\end{tabular}

Consequently, judgmental sampling was adopted to select the participants to conduct the semi-structured interviews. Judgmental sampling is a non-probability sampling technique in which sampling units are selected solely based on the researcher's knowledge and judgment (Westfall, 2008). Accordingly, selected cases had few professionals who have experience with smart integration. Therefore, due to the unavailability of professionals with adequate knowledge in smart applications and time constraints, the interviews are limited to one professional in each case. However, selected participants have reasonable experience in the field of study to respond to the questions to address the objectives of this study. Respondents' details are interpreted in Table 2.

Table 2: Profile of interview participants of selected cases

\begin{tabular}{cclc}
\hline Cases & Participant Code & \multicolumn{1}{c}{ Designation } & Experience \\
\hline C1 & P1 & Facilities Manager & 6 Years \\
C2 & P2 & Assistance Manager Engineer & 10 Years \\
C3 & P3 & Facilities Manager & 6 Years \\
C4 & P4 & Maintenance Engineer, Mechanical & 20 Years \\
C5 & P5 & Former General Manager-Facilities Management & 25 Years \\
\hline
\end{tabular}

Thereafter, the qualitative data collected was analysed using manual content analysis and computer software with the aid of NVivo 12 software. 


\section{RESEARCH FINDINGS AND DISCUSSION}

\subsection{Current Energy Saving Mechanisms}

In order to identify the energy-saving mechanisms to evaluate the level of energy consumption practised in the selected cases, participants of the selected cases were asked to comment on their current practices of energy-saving and mechanisms practised. Table 3 includes the summary of energy-saving mechanisms in selected cases.

Table 3: Summary of energy-saving mechanisms

\begin{tabular}{lccccc}
\hline \multicolumn{1}{c}{ Cases } & C1 & C2 & C3 & C4 & C5 \\
\hline Thermal Performance of Building Envelope & $\checkmark$ & & & & $\checkmark$ \\
Building Orientation, Form, and Thermal mass & $\checkmark$ & $\checkmark$ & $\checkmark$ & $\checkmark$ & $\checkmark$ \\
Passive Heating, Cooling, and Ventilation & $\checkmark$ & & $\checkmark$ & & $\checkmark$ \\
Daylighting & $\checkmark$ & $\checkmark$ & $\checkmark$ & & $\checkmark$ \\
Properly Sized Energy-Using Devices & & $\checkmark$ & $\checkmark$ & $\checkmark$ & $\checkmark$ \\
BMS Integration & $\checkmark$ & $\checkmark$ & $\checkmark$ & & $\checkmark$ \\
Building Automation/Smart Features & $\checkmark$ & $\checkmark$ & $\checkmark$ & $\checkmark$ & $\checkmark$ \\
\hline
\end{tabular}

\subsection{CURRENT LEVEL OF APPLiCABility OF SMART FEATURES}

To identify the current level of applicability of smart features in the selected cases, participants of selected cases were asked to comment on the smart features that are integrated within the buildings, which is tabulated in Table 4. In addition, the level of subsystem integration and measures practised in the industry to assess the efficiency of smart features can be used as measures to assess the applicability of smart features.

Table 4: Current smart feature practices

\begin{tabular}{|c|c|c|c|c|c|}
\hline Cases & C1 & $\mathbf{C 2}$ & $\mathbf{C 3}$ & $\mathbf{C 4}$ & C5 \\
\hline Sensors & $\checkmark$ & $\checkmark$ & $\checkmark$ & $\checkmark$ & $\checkmark$ \\
\hline Smart metering & & $\checkmark$ & $\checkmark$ & & $\checkmark$ \\
\hline Smart lighting & $\checkmark$ & $\checkmark$ & & $\checkmark$ & $\checkmark$ \\
\hline Distributed generation, energy storage, and net metering & $\checkmark$ & & $\checkmark$ & & \\
\hline Smart building energy management system & & $\checkmark$ & & & $\checkmark$ \\
\hline \multicolumn{6}{|l|}{ Smart grid and energy internet } \\
\hline Smart HVAC technologies & $\checkmark$ & $\checkmark$ & $\checkmark$ & $\checkmark$ & $\checkmark$ \\
\hline $\begin{array}{l}\text { Predefined events (calendar events, emergency events, } \\
\text { periodic events) }\end{array}$ & $\checkmark$ & $\checkmark$ & $\checkmark$ & & $\checkmark$ \\
\hline
\end{tabular}

\subsection{SUBSYSTEM INTEGRATION}

A comprehensive literature review emphasised that smart features can integrate all the available systems in the building and are convenient for operation by better coordination among those systems. However, case study findings indicated a completely different indication of current industry practice regarding subsystem integration. The subsystems' availability and smart feature integration of selected five cases are illustrated in Figure 1. 


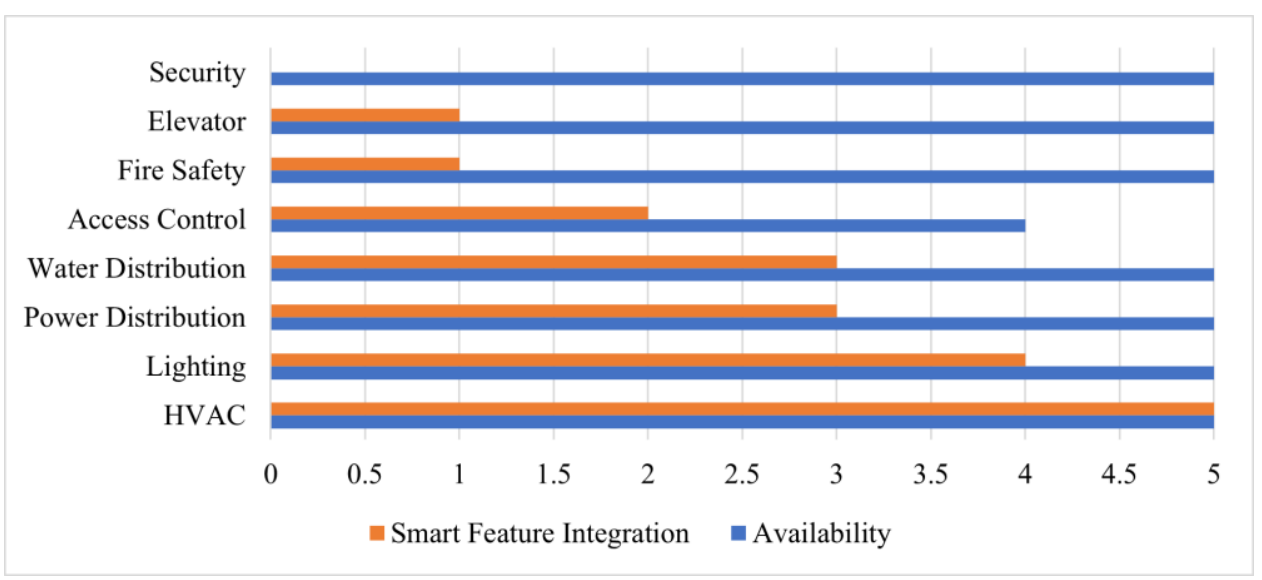

Figure 1: Subsystem availability and smart feature integration

All the selected cases have integrated with major seven systems, but they do not fully incorporate their subsystems with smart features for operation. In addition, it was found that HVAC, lighting, and power distribution are the main systems in the building and the focus of smart feature integration is more towards that.

When looking into integration, smart features are mainly used as a monitoring device and energy meter in most cases. It is evidenced that the capabilities of smart features are not fully utilised by building practitioners in commercial buildings. The level of integration of each system is illustrated in Figure 2.

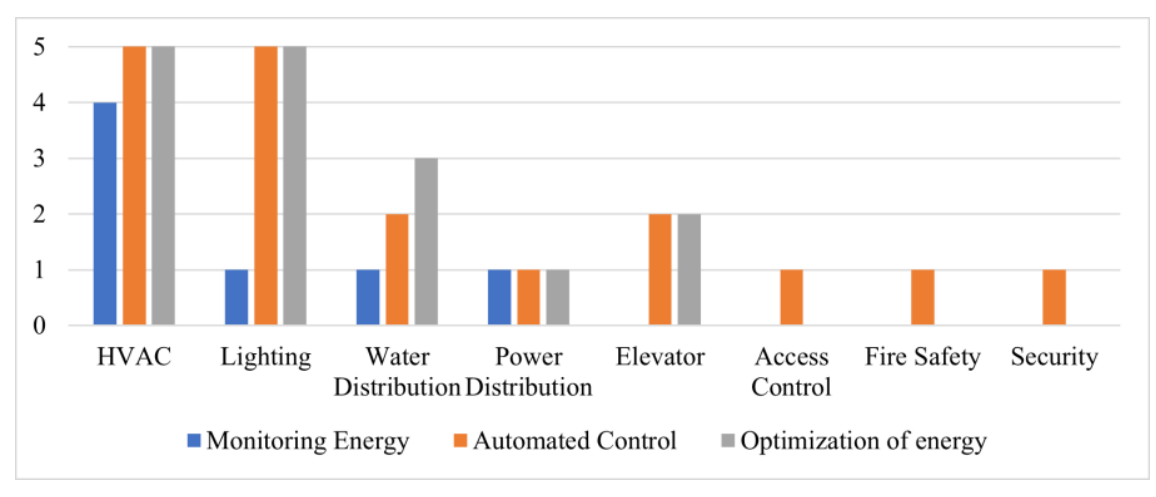

Figure 2: Level of smart feature integration

Concerning the findings, each case has a different level of subsystem integration to smart features. Mostly smart features are used to automatically control the subsystems rather than monitoring and optimise the energy. Although all the systems are integrated, only HVAC and lighting are used to a broader extent than other systems. According to the analysis, all the selected cases are clustered into three major groups based on subsystem integration as high, medium, and low, summarised in Table 5.

Table 5: Summary of subsystem integration

\begin{tabular}{ccc}
\hline Level of Subsystem Integration & Cases & Building Type \\
\hline High & $\mathrm{C} 5$ & Commercial office \\
Medium & $\mathrm{C} 1, \mathrm{C} 2, \mathrm{C} 3$ & Bank and Commercial \\
Low & $\mathrm{C} 4$ & Bank \\
\hline
\end{tabular}


Concerning the findings, only HVAC and lighting are used to a broader extent than other systems in the Sri Lankan context. Further, findings revealed that there is no perfect smart feature practiced in the local context.

\subsection{ENERGY EFFICIENCY ASSESSMENT}

Based on the findings, it is evident that smart features save considerable energy compared to buildings that are not integrated with smart features. All cases integrate smart features mainly for energy-saving purposes. However, the energy-saving potential of smart features is not regularly checked by all the cases, as given in Table 6 .

Table 6: Energy efficiency assessment practice

\begin{tabular}{cll}
\hline Cases & Assessment Frequency & \multicolumn{1}{c}{ Saving potential } \\
\hline C3 & Annually & Save 50\% of building energy consumption \\
C5 & Monthly & Save 10 to 20\% of building energy consumption \\
C2 & Once at the initial stage & Save 20\% of energy consumption \\
C1 & Once at the initial stage & Save 10\% of energy consumption \\
C4 & Annually & Save 8 to 10\% of energy consumption \\
\hline
\end{tabular}

\subsection{BARRIERS TO IMPLEMENT SMART FEATURES}

Barriers to implementing smart features efficiently in commercial buildings in Sri Lanka were evaluated using code-based content analysis. Interviewees were asked to comment on the barriers for integrating smart features, and their responses were analysed using code-based content analysis to collect the participant's perspective on the barriers. The results are illustrated in Figure 3.

\begin{tabular}{|c|c|c|c|c|}
\hline \multicolumn{5}{|l|}{ Codes } \\
\hline (4) 1 & ame & $\leftrightarrow$ & Files & References \\
\hline$\rightarrow O \quad \mathrm{~B}$ & arriers & & 5 & 47 \\
\hline-0 & High initial cost & & 5 & 6 \\
\hline-0 & Uncompetitive market price & & 4 & 4 \\
\hline-0 & Lack of financial sources & & 1 & 1 \\
\hline-0 & Limited knowledge of management, building owners and operators & & 5 & 9 \\
\hline-0 & Lack of understanding about the system among the customers & & 4 & 5 \\
\hline-0 & Poor participation of stakeholders & & 1 & 1 \\
\hline-0 & Age of building & & 2 & 3 \\
\hline-0 & Owner and operators are reluctant to adopt to new technologies & & 3 & 3 \\
\hline-0 & Threats to cybersecurity & & 1 & 1 \\
\hline-0 & Lack of workforce skill & & 5 & 7 \\
\hline-0 & Equipment compatibility issues & & 3 & 3 \\
\hline L & Lack of vendors and contractors & & 3 & 4 \\
\hline
\end{tabular}

Figure 3: Barriers for smart features integration

\subsection{MECHANISMS FOR BETTER INTEGRATION OF SMART FEATURES}

Strategies to enhance the performance of smart features towards efficient building operation in the Sri Lankan context were gathered through the participants' opinions and analysed, which are illustrated in Figure 4. 
There are no specific studies that seem to have existed in the literature. However, analysis findings revealed that raising awareness of management and client, selecting reliable contractor, designing accordance with operation, assigning experienced operator, industrial cybersecurity standards, train operators and workforce, sufficient technical support, introducing building regulations, proper commissioning, selecting suitable vendor, pilot project, and continuous knowledge enhancement are the mechanisms proposed to mitigate the prevailing barriers.

\begin{tabular}{|c|c|c|c|}
\hline \multicolumn{4}{|l|}{ Codes } \\
\hline$(4)$ & Name & $\leftrightarrow$ Files & References \\
\hline \multicolumn{2}{|c|}{ - $O$ Mechanisms } & 5 & 50 \\
\hline-0 & Raise awareness of management and client & 3 & 5 \\
\hline - & Select reliable contractor & 5 & 7 \\
\hline $\mathrm{O}$ & Design accordance with operation & 5 & 8 \\
\hline-0 & Assign experience operator & 3 & 3 \\
\hline-0 & Industrial cybersecurity standards & 1 & 2 \\
\hline $\mathrm{O}$ & Train operators and workforce & 5 & 8 \\
\hline-0 & Sufficient technical support & 5 & 5 \\
\hline 0 & Introducing building regulations & 2 & 3 \\
\hline-0 & Proper commissioning & 2 & 2 \\
\hline-0 & Select suitable vendor & 4 & 4 \\
\hline 0 & Pilot project & 1 & 2 \\
\hline 0 & Continuous knowledge enhancement & 3 & 4 \\
\hline
\end{tabular}

\subsection{DISCUSSION OF FINDINGS}

The literature findings show that smart buildings are the current trend to conserve energy in commercial buildings. Similarly, according to case study findings, Sri Lankan commercial buildings are also in the stage of adopting new technologies, and smart features also be a part of it. All the participants emphasised that sensors and smart HVAC technologies are widely used in buildings to reduce energy consumption. In addition, smart lighting and predefined events are used as smart features. Moreover, smart metering is used to control energy consumption in commercial buildings.

In addition, the level of subsystem integration was checked in the selected cases. Smart features are integrated with several subsystems in commercial buildings. In addition, major subsystems that are commonly integrated into the buildings were identified, such as HVAC, lighting, security and access control, water distribution, power distribution, fire safety and an elevator (Aste et al., 2017; Doukas et al., 2007; Shaik et al., 2014). The case study findings emphasised that none of the cases integrates all available systems with smart features. Most building practitioners focused on HVAC and lighting rather than all the other systems.

Moreover, the level of subsystem integration is grouped into three groups as high, medium and low. Further, integrated systems are not fully utilised. Most of the cases are integrated with the smart features only to control the system automatically. Further, energy efficiency was assessed. Literature emphasised that energy saving is the most significant benefit which can be achieved through smart features integration. Furthermore, all the participants agreed that smart features save considerable energy 
compared to buildings that are not integrated with smart features. All cases integrate smart features mainly for energy-saving purposes.

Literature findings emphasised that there are several issues in integrating smart features within the buildings. In such context, case study findings highlighted that all the significant barriers identified in the literature greatly impact smart features integration. The uncompetitive market price for smart features, lack of financial sources, age of the building, owner and operators are reluctant to adapt to new technologies, and lack of vendors and contractors are identified as major barriers in addition to the literature findings. However, identified barriers have a huge role in the integration of smart features. Therefore, for the better integration of smart features, such barriers need to be mitigated.

\subsection{FRAMEWORK FOR THE BETTER INTEGRATION OF SMART FEATURES IN COMMERCIAL BUILDINGS}

In order to accomplish this aim, a framework was developed, as shown in Figure 5, from the overall findings of this research. The framework includes three models developed based on the level of subsystem integration with smart features.

Further, the barriers were linked with the models and revealed the reasons for the lack of integration of smart features with respect to the models. Moreover, the framework elaborates on the mechanisms that need to be used to overcome those aforementioned barriers to better integrate smart features in commercial buildings. Thus, the framework supports commercial building practitioners for the better integration of smart features towards energy conservation.

\section{CONCLUSIONS}

Different energy-saving mechanisms are practised in existing commercial buildings, and smart buildings are one of the current energy-saving mechanisms emerging in Sri Lankan commercial buildings. Through the research, it is evident that several commercial buildings practised smart features in buildings and conserve energy to a vast extent. However, it is evident that the integration of smart features in commercial buildings is not practised widely. Several barriers to integrating smart features in buildings have been identified in this research. Besides, identified barriers have a huge role in the integration of smart features. Therefore, for the better integration of smart features, those barriers need to be mitigated. Therefore, possible mechanisms were developed based on the opinions of industry practitioners. Arising awareness of management and client, selecting reliable contractor, designing accordance with operation, assigning experienced operator, industrial cybersecurity standards, training operators and workforce, sufficient technical support, introducing building regulations, proper commissioning, selecting suitable vendor, pilot project and continuous knowledge enhancement are the mechanisms proposed to mitigate the prevailing barriers. Finally, a framework was developed, and the framework supports commercial building practitioners for the better integration of smart features towards energy conservation. The findings of this report will help commercial building professionals in the industry to enhance the integration of smart features in Sri Lanka to conserve energy. Therefore, making aware of the subsystems that can be integrated with smart features and allowing better coordination among those systems and formulating possible mechanisms will allow better integration of smart features within the buildings. 


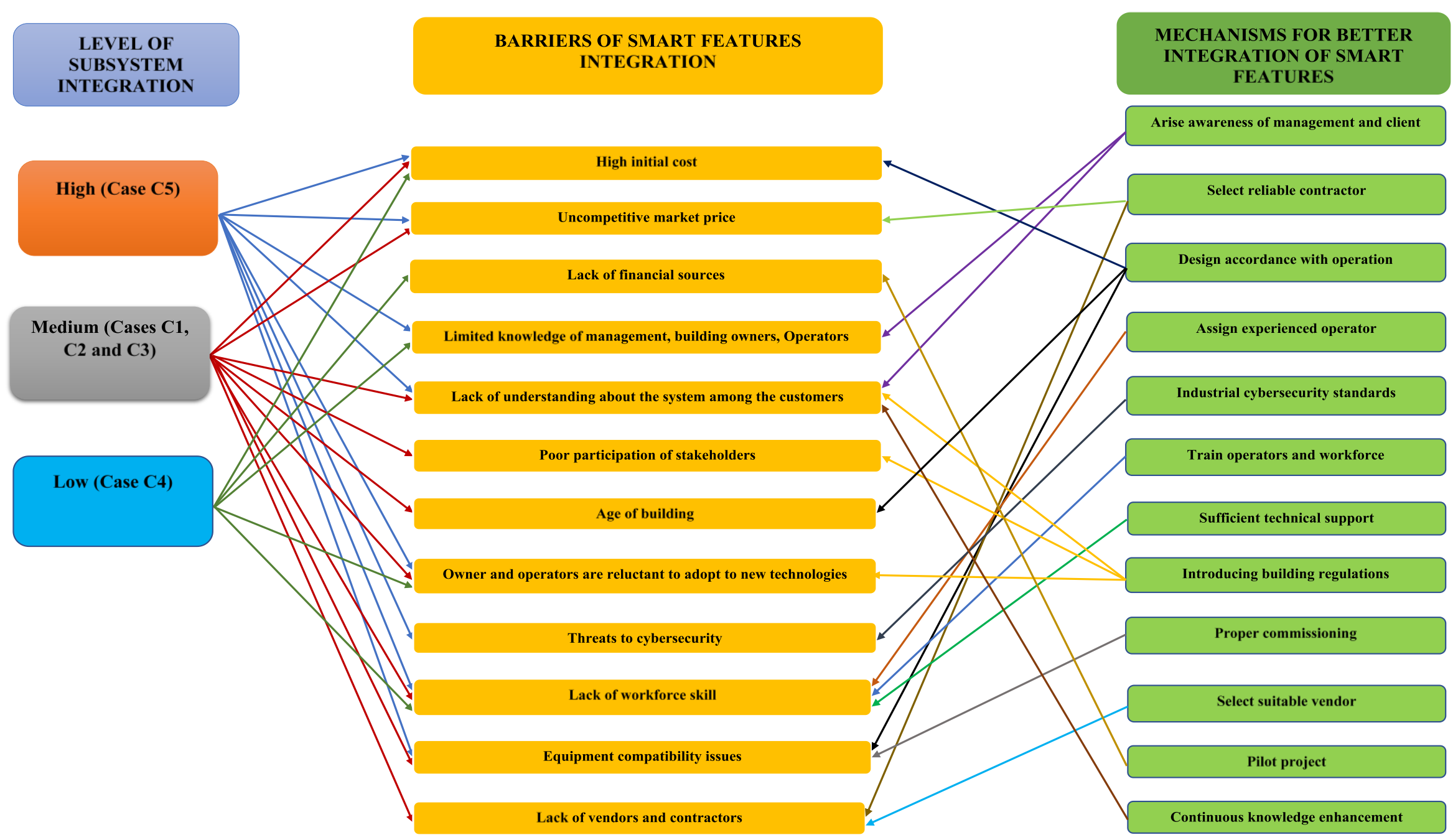

Figure 5: Framework for the better integration of smart features in commercial buildings 


\section{REFERENCES}

Albino, V., Berardi, U. and Dangelico, R.M., 2015. Smart cities: Definitions, dimensions, performance, and initiatives. Journal of Urban Technology, 22(1), pp. 3-21.

Anik, D., Boonstra, C. and Mak, J., 2016. Handbook of sustainable building. London: James \& James Ltd.

Arditi, D., Mangano, G. and De Marco, A., 2015. Assessing the smartness of buildings. Facilities, 33(9/10), pp. 553-572.

Atayero, A.A., Oluwatobi, S.O. and Alege, P.O., 2016. An assessment of the Internet of Things (IoT) adoption readiness of Sub-Saharan Africa. Journal of South African Business Research, pp. 1-13.

Basnayake, J., Amarasinghe, R., Attalage, R. and Udayanga, T., 2015. Artificial intelligence based smart building automation controller for energy efficiency improvements in existing buildings. International Journal of Advanced Information Science and Technology, 40, pp. 150-156.

Brady, L. and Abdellatif, M., 2017. Assessment of energy consumption in existing buildings. Energy and Buildings, 149, pp. 142-150.

Buckman, A. H., Mayfield, M. and Beck, S. B. M., 2014. What is a smart building. Smart and Sustainable Built Environment, 3(2), pp. 92-109.

Central Intelligence Agency [CIA], 2019. [Online] Available from: https://www.indexmundi.com/g/g.aspx?c=ce\&v=81

Ceylon Electricity Board [CEB], 2018. Annual Report 2018, Colombo.

Chwieduk, D., 2003. Towards sustainable energy buildings. Applied Energy, 76, pp. 211-217.

Dincer, I., 1999. Energy and environmental impacts: present and future perspectives. Energy Sources, 20(4:5), pp. 427-453.

Doukas, H., Patlitzianas, K. D., Iatropulos, K. and Psarras, J., 2017. Intelligent building energy management system using rule sets. Building and Environment, 42(10), pp. 3562-3569.

Fasna, M.F.F. and Gunatilake, S., 2019. Energy retrofits to enhance energy performance of existing buildings: A review. In: Sandanayake, Y.G., Gunatilake, S. and Waidyasekara, A. (eds). Proceedings of the $8^{\text {th }}$ World Construction Symposium, Colombo, Sri Lanka, 8-10 November 2019, pp. 308-319. Available from: https://2019.ciobwcs.com/papers

Fernando, M. N. and Jayasena, H. S., 2008. Practising energy efficient design for commercial buildings in Sri Lankan industry. [Online] Available from: http://www.suranga.net/publications/2008_energy_efficient_design.pdf, 2008.

Gluszak, M., Gawlik, R. and Zieba, M., 2019. Smart and green buildings features in the decision-making hierarchy of office space tenants: An analytic hierarchy process study. Administrative Sciences, 9(3), $\mathrm{p}$. 52.

Hojjati, S.N. and Khodakarami, M., 2016. Evaluation of factors affecting the adoption of smart buildings using the technology acceptance model. International Journal of Advanced Networking and Applications, 7(6), pp. 2936-2943.

International Organisation for Standardization [ISO], 2018. Energy management systems. pp. 1-12.

Jayamaha, L., 2006. Energy efficient building systems: Green strategies for operation and maintence. McGraw-Hill Companies.

Kaygusuz, K., 2002. Environmental impacts of energy utilisation and renewable energy policies in Turkey. Energy Policy, 30, pp. 689-698.

King, J. and Perry, C., 2017. Smart buildings: Using smart technology to save energy in existing buildings. Washington: American Council for an Energy-Efficient Economy.

Madani, F., Daim, T. and Weng, C., 2017. 'Smart building technology network analysis: Applying coreperiphery structure analysis. International Journal of Management Science and Engineering Management, 12(1), pp. 1-11.

Mammeri, Z. and Younus, M.U., 2018. Software-defined networking for smart buildings: Advances and challenges. Guimaraes.

Ma, Z., Badi, A. and Jørgensen, B.N., 2016. Market opportunities and barriers for smart buildings. Long Beach, CA, USA: IEEE. 
Nguyen, A. and Aiello, M., 2013. Energy intelligent buildings based on user activity: A survey. Energy and Buildings, 56, pp. 244-257.

Pathmasiri, M.M.R., 2010. Code of practice for energy efficient buildings in Sri Lanka. SLEMA .

Rana, N.P., Luthra, S. and Mangla, S.K., 2019. Barriers to the development of smart cities in Indian context. Information Systems Frontiers, 21, pp. 503-525.

Sembroiz, D., Careglio, D., Ricciardi, S. and Fiore, U., 2019. Planning and operational energy optimisation solutions for smart buildings. Information Sciences, pp. 439-452.

Shabha, G., 2006. A critical review of the impact of embedded smart sensors on productivity in the workplace. Facilities, 24(13/14), pp. 538-549.

Suriyarachchi, C., Waidyasekara, K.G.A.S. and Madhusanka, N., 2019. Integrating internet of things (IoT) and facilities manager in smart buildings: a conceptual framework. Colombo, pp. 325-334.

Vidanagama, J. and Lokupitiya, E., 2018. Energy usage and greenhouse gas emissions associated with tea and rubber manufacturing processes in Sri Lanka. Environmental Development, 26, pp. 43-54.

Westfall, L., 2008. Sampling Methods. ASQ Quality Press.

Woradechjumroen, D. and Li, H., 2015, June. Building energy efficiency improvement via smart building solutions: Introduction to methodologies. In International Conference on Computer Information Systems and Industrial Applications (CISIA), pp. 980-982.

Yang, L., Yan, H. and Lam, J.C., 2014. Thermal comfort and building energy consumption implications A review. Applied Energy, 115, p. 164-173.

Zavalani, O., 2011. Reducing energy in buildings by using energy management systems and alternative energy-saving systems. Zagreb, IEEE.

Zhao, H. and Magoules, F., 2012. A review on the prediction of building energy consumption. Renewable and Sustainable Energy Reviews, 16, pp. 3586-3592.

Zhou, K. and Yang, S., 2018. Smart energy management. Comprehensive Energy Systems, 5, pp. 423-456.

Zou, P. X. W., Xu, X., Sanjayan, J. and Wang, J., 2018. Review of 10 years research on building energy performance gap: Life-cycle and stakeholder perspectives. Energy and Buildings, 178, pp. 165-181.

Zuo, J., Read, B., Pullen, S. and Shi, Q., 2012. Achieving carbon neutrality in commercial building developments - Perceptions of the construction industry. Habitat International, 36, pp. 278-286. 